\title{
Co-expression of Nisin Z and Leucocin $C$ as a Basis for Effective Protection Against Listeria monocytogenes in Pasteurized Milk
}

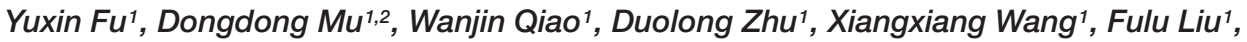
Haijin Xu1 ${ }^{1}$, Per Saris ${ }^{3}$, Oscar P. Kuipers ${ }^{4}$ and Mingqiang Qiao ${ }^{1 *}$

${ }^{1}$ Key Laboratory of Molecular Microbiology and Technology, Ministry of Education, Nankai University, Tianjin, China, ${ }^{2}$ Key Laboratory for Agricultural Products Processing of Anhui Province, Hefei University of Technology, Hefei, China, ${ }^{3}$ Department of Food and Environmental Sciences, University of Helsinki, Helsinki, Finland, ${ }^{4}$ Department of Molecular Genetics, Groningen Biomolecular Sciences and Biotechnology Institute, University of Groningen, Groningen, Netherlands

OPEN ACCESS

Edited by:

Vittorio Capozzi,

University of Foggia, Italy

Reviewed by:

Charles M. A. P. Franz,

Max Rubner-Institut Karlsruhe,

Germany

Anca loana Nicolau

"Dunarea de Jos" University of Galati,

Romania

${ }^{*}$ Correspondence:

Mingqiang Qiao

mingqiangqiao@aliyun.com

Specialty section:

This article was submitted to

Food Microbiology,

a section of the journal

Frontiers in Microbiology

Received: 29 December 2017 Accepted: 09 March 2018

Published: 23 March 2018

Citation:

Fu Y, Mu D, Qiao W, Zhu D, Wang X, Liu F, Xu H, Saris P, Kuipers $O P$ and Qiao M (2018) Co-expression of Nisin

$Z$ and Leucocin $C$ as a Basis for Effective Protection Against

Listeria monocytogenes in Pasteurized Milk.

Front. Microbiol. 9:547.

doi: 10.3389/fmicb.2018.00547
Nisin, an important bacteriocin from Lactococcus lactis subsp., is primarily active against various Gram-positive bacteria. Leucocin C, produced by Leuconostoc carnosum 4010, is a class Ila bacteriocin used to inhibit the growth of Listeria monocytogenes. Because two bacteriocins have different modes of action, the combined use of them could be a potential strategy for effective inhibition of foodborne pathogens. In this study, L. lactis N8-r-lecCl (N8 harboring lecCl gene) coexpressing nisin-leucocin $\mathrm{C}$ was constructed based on the food-grade carrier L. lactis N8. Production of both bacteriocins was stably maintained. Antimicrobial measurements showed that the recombinant strain is effectively against Listeria monocytogenes and Staphylococcus aureus and moderately against Salmonella enterica serovar Enteritidis and Escherichia coli because of its stronger antibacterial activity than the parental strain, this result first demonstrated that the co-expression of nisin and leucocin $\mathrm{C}$ results in highly efficient antimicrobial activity. The checkerboard assay showed that the antibacterial activity of $L$. lactis N8-r-lecCl supernatant was enhanced in the presence of low concentration of EDTA. Analysis of the scanning electron microscope image showed the biggest cellular morphology change in $L$. monocytogenes treated with a mixture of EDTA and $L$. lactis N8-r-lecCl supernatant. The practical effect was verified in pasteurized milk through time-kill assay. The L. lactis N8-r-lecCl strain expressing both nisin and leucocin $\mathrm{C}$ has a promising application prospect in pasteurized milk processing and preservation because of its strong antibacterial activity.

Keywords: foodborne pathogens, Listeria monocytogenes, nisin, leucocin C, Lactococcus lactis, antimicrobial activity

\section{INTRODUCTION}

Pathogen control is a significant issue in the food industry. Foodborne diseases can spread further and more rapidly than before because of the increasing transnational trade, travel, and migration (Kaferstein et al., 1997). Although various measures have been implemented to decrease infections caused by foodborne pathogens (Gandhi and Chikindas, 2007), foodborne disease outbreaks from

Abbreviations: EDTA, ethylenediaminetetraacetic acid; lecCI, bacteriocin leucocin $\mathrm{C}$ and its immunity gene. 
microbial contamination, chemicals, and toxins remain prevalent worldwide (Velusamy et al., 2010). For example, in the outbreak of listeriosis in the United States in September 2011, a total of 146 invasive illnesses, 30 deaths, and 1 miscarriage were recorded (Laksanalamai et al., 2012). The foodborne pathogen Listeria, the causative agent of listeriosis (Yousef and Lou, 1999), can grow at refrigeration temperatures and adapt to low $\mathrm{pH}$ and high salt concentration (Cole et al., 1990). As such, this pathogen can overcome various bacteriostatic measures, increasing the difficulty of anti-listeria treatments.

Researchers have developed various methods for controlling foodborne pathogens to reduce their potential risks to human health (Gandhi and Chikindas, 2007). Such methods include the addition of bacteriocins and bacteriocin-producing lactic acid bacteria (LAB) in food (Roberts and Zottola, 1993) as effective alternatives to chemical preservatives (Lucera et al., 2012). Lactococcus, Lactobacillus, Leuconostoc, and other LAB can secrete bacteriocins (Barefoot and Klaenhammer, 1983; Klaenhammer, 1993; Wan et al., 2013, 2015), which are ribosomally synthesized and extracellularly released peptides with antimicrobial activity. LAB bacteriocin has been widely characterized because of their "food-grade quality" and industrial importance (Barbosa et al., 2017). Nisin, an important bacteriocin from $\mathrm{LAB}$, is primarily active against Gram-positive bacteria (Delves-Brougthon, 1990). Nisin is used as a food protection agent in more than 60 countries and regions worldwide because of its low toxicity and high efficiency. In addition to nisin, one of the available commercial antibacterial agents (Barbosa et al., 2017), other bacteriocins exhibit promising perspectives. Class IIa bacteriocin piscicolin P126 displays antilisterial activity in milk and Camembert cheese (Wan et al., 1997). Enterocin AS48 is active against Alicyclobacillus acidoterrestris, which is a spoilage-causing bacterium in fruit juices (Grande et al., 2005). Leucocin C kills the foodborne pathogen Listeria monocytogenes, and leucocin C-producing strain Leuconostoc carnosum 4010 is used as protective culture in meat products (Wan et al., 2013).

Bacteriocins confer protection against foodborne pathogens; however, single application of bacteriocins is hindered by their limited activity spectrum, high concentration demand and the prevalence of antimicrobial resistance. Several studies have demonstrated that some bacteriocins show additive or synergistic effects when used in combination with other antimicrobial agents; in this regard, combining bacteriocins is a good alternative to the use of single bacteriocin for effective pathogen inhibition. For example, the combination of nisin and its variants with carvacrol and/or citric acid inhibited Gram-negative foodborne pathogens (Campion et al., 2017). The activity of lysozyme and nisin against L. monocytogenes and Escherichia coli was enhanced with the addition of EDTA (Branen and Davidson, 2004). The efficacy of the antibiotics polymyxin and colistin for preventing the biofilm formation of Pseudomonas aeruginosa increased when they were combined with nisin treatment (Field et al., 2016).

In this study, a strain of L. lactis stably coexpressing nisinleucocin $\mathrm{C}$ was constructed to control a wide range of foodborne pathogens, including L. monocytogenes. LAB are generally recognized as safe (GRAS) microorganisms and widely used in dairy and fermented food (Roberts and Zottola, 1993; O'Sullivan et al., 2002; Swetwiwathana and Visessanguan, 2015). Application of bacteriocin-producing LAB strains may be more effective than direct addition of preservatives because of the continuous in situ production of bacteriocins (Langa et al., 2017). However, the use of genetically modified lactic acid bacteria (GM-LAB) was not widely applied and accepted in many Countries (Sybesma et al., 2006). Risk assessment and expected benefits will determine the future use of GM-LAB in the domains of food technology and health (Renault, 2002; LeBlanc et al., 2010; Capozzi et al., 2012). We aimed to construct a L. lactis strain, based on food-grade biotechnological strategy, with improved antimicrobial activity and broad antimicrobial spectrum without using genes from nonGRAS bacteria and antibiotics selection pressure for maintaining genetic stability.

\section{MATERIALS AND METHODS}

\section{Plasmids, Strains, and Growth Conditions}

Lactococcus lactis N8 (N8) (Qiao et al., 1996), a wild-type (WT) nisin Z producer, and L. lactis NZ9000 (NZ9000) (Kuipers et al., 1998), which is usually used as cloning host, were cultured without agitation at $30^{\circ} \mathrm{C}$ in SGM17 broth [M17 broth supplemented with $0.5 \%$ (w/v) glucose and $0.55 \%(\mathrm{w} / \mathrm{v})$ sucrose]. When needed the broth was supplemented with $10 \mathrm{ng} / \mathrm{mL}$ nisin for induction expression. Antibiotic susceptibility screening was conducted using $150 \mu \mathrm{g} / \mathrm{mL}$ erythromycin (Em) and $15 \mu \mathrm{g} / \mathrm{mL}$ chloramphenicol $(\mathrm{Cm})$ for E. coli $\mathrm{DH} 5 \alpha$ and $5 \mu \mathrm{g} / \mathrm{mL}$ Em and $5 \mu \mathrm{g} / \mathrm{mL}$ Cm for L. lactis.

Escherichia coli O157:H7, L. monocytogenes WSLC 1018, and Micrococcus luteus A1CNCIMB861666 were obtained from our laboratory. E. coli ATCC8739, Staphylococcus aureus ATCC29213, Salmonella Enteritidis ATCC14128, S. aureus ATCC6538, and L. monocytogenes ATCC 19115 were obtained from the Guangdong Culture Collection Center. Except for nisin-sensitive indicator strain M. luteus A1CNCIMB861666 and leucocin C-sensitive indicator strain L. monocytogenes WSLC 1018 , all these strains are common foodborne pathogens and used as indicator in this study. These strains were cultured in LB broth (Hope Bio, Qingdao, China), except for L. monocytogenes, which was cultured in TSB-YE broth (Hope Bio, Qingdao, China).

Plasmids used in this study are listed in Table 1. pLEB124 was used to construct the expression vector. pNZ5319 was used to express lecCI (Leucocin $\mathrm{C}$ and its immunity gene) in the chromosome of $\mathrm{N} 8$ through $\mathrm{Cre}-$ loxP gene recombination system.

\section{Construction of Leucocin C Expression Strains}

The plasmid pLEB729 (Wan et al., 2013) was digested with HindIII and BamHI (Takara, Dalian, China) to obtain the expression fragment $\mathrm{P}_{\text {nisZ }}+$ SSusp45+lecCI. The fragment was 
TABLE 1 | Plasmids used in this study.

\begin{tabular}{|c|c|c|}
\hline Plasmids & Relevant properties & Reference \\
\hline pLEB690 & $\begin{array}{l}\text { L. lactis secretion vector harboring } \\
\text { lactococcal promoters } \mathrm{P}_{45} \text { and } \\
\mathrm{P}_{\text {nisz, and signal sequence }} \\
\text { SSusp } 45\end{array}$ & Li et al., 2011 \\
\hline pLEB729 & $\begin{array}{l}\text { Leucocin C and the immunity gene } \\
\text { lecCl fused to SSusp } 45 \text { in pLEB690 }\end{array}$ & Wan et al., 2013 \\
\hline pLEB124 & $\begin{array}{l}\text { L. lactis secretion vector harboring } \\
\text { lactococcal promoter } \mathrm{P}_{45}\end{array}$ & Qiao et al., 1995 \\
\hline pLEB124-lecCl & $\begin{array}{l}\text { fragment }\left(\mathrm{P}_{\text {nisz }}+\text { SSUsp } 45+l e c C l\right) \\
\text { obtained from pLEB729 cloned into } \\
\text { pLEB124 }\end{array}$ & This study \\
\hline pNZ5319 & $\begin{array}{l}\text { vector for gene replacements in } \\
\text { Gram-positive bacteria }\end{array}$ & $\begin{array}{l}\text { Lambert et al., } \\
2007\end{array}$ \\
\hline pNZ5319-up-down & $\begin{array}{l}\text { Upstream and downstream } \\
\text { sequences of the N8GL37-38 } \\
\text { genes cloned into pNZ5319 }\end{array}$ & This study \\
\hline $\begin{array}{l}\text { pNZ5319-up- } \\
\text { down-lecCl }\end{array}$ & $\begin{array}{l}\text { Fragment } \\
\left(\mathrm{P}_{45}+\mathrm{P}_{\text {nisz }}+\mathrm{SS} \text { S sp45+lecCl) }\right. \\
\text { obtained from pLEB124-lecCl } \\
\text { replaced the cat gene in } \\
\text { pNZ5319-up-down }\end{array}$ & This study \\
\hline
\end{tabular}

purified with DNA gel extraction kit (Solarbio, Beijing, China) and cloned into HindIII-BamHI digested pLEB124 to produce pLEB124-lecCI. pLEB124-lecCI was then electroporated into L. lactis NZ9000 and L. lactis N8 to obtain NZ9000-p-lecCI and N8-p-lecCI (plasmid expression method) expression strains, respectively.

The non-necessary genes N8GL37-38 were replaced with lecCI to stably express lecCI in the genome of N8 without antibiotic pressure. In brief, 633-bp upstream and 528-bp downstream sequences of the N8GL37-38 genes were amplified with the N8 genome as template by using LA Taq (Takara, Dalian, China) and cloned into the XhoI-SwaI and SacI-BglII restriction sites of pNZ5319, respectively, to obtain the pNZ5319-up-down vector. $\mathrm{P}_{45}+\mathrm{P}_{\text {nisZ }}+$ SSusp45+lecCI was amplified with the pLEB124lecCI as template by PCR using Phusion High-Fidelity DNA polymerase (Thermo Fisher, China) with primer pairs LecC F/R. PCRs were performed using the primers listed in Table 2. The PCR products and pNZ5319-up-down were digested with BglII and XhoI and then cloned into the BglII-XhoI sites of pNZ5319up-down to replace the cat gene and obtain the recombination vector pNZ5319-up-down-lecCI, which was introduced into N8. The genomes of transformants and N8 were used as templates to amplify the target genes with the primers Ery-F/R, LecCI$\mathrm{F} / \mathrm{R}$, and Out-F/R to identify the single or double cross-over recombinants. The PCR products were analyzed on $1 \%$ agarose gels. The potential nisin and leucocin $\mathrm{C}$ co-expression strain N8-r-lecCI (homologous recombination expression method) was identified.

\section{Growth Profile of Wild and Constructed Strains}

N8, N8-p-lecCI, and N8-r-lecCI were cultured to $\mathrm{OD}_{600}$ of 0.8 in the SGM17 broth and diluted to an optical density of $\mathrm{OD}_{600}$ of
TABLE 2 | Primers used in this study.

\begin{tabular}{|c|c|c|}
\hline Primer & Sequence $\left(5^{\prime}-3^{\prime}\right)$ & $\begin{array}{l}\text { Annealing } \\
\text { temperature }\left({ }^{\circ} \mathrm{C}\right)\end{array}$ \\
\hline \multicolumn{3}{|c|}{$\begin{array}{l}\text { For the construction of leucocinC expression vector } \\
\text { (pNZ5319-up-down-lecCl) }\end{array}$} \\
\hline UP-F & $\begin{array}{l}\text { CCGCTCGAG } \\
\text { AGATGAGGGTAATCTGAAGGA }\end{array}$ & 52 \\
\hline UP-R & $\begin{array}{l}\text { СССАТТТААТ } \\
\text { АССТTATСТTAАATGССТАТСТT }\end{array}$ & \\
\hline Down-F & $\begin{array}{l}\text { CCCGAGCTC } \\
\text { GAAAGGGGGATTAGTGATCA }\end{array}$ & 54 \\
\hline Down-R & $\begin{array}{l}\text { GAAGATCT } \\
\text { ACTCGCTACCGCCTGAAA }\end{array}$ & \\
\hline LecCl-F & CGTTAGGGGCTTGAACAAG & 56 \\
\hline LecCl-R & CTAATATCCATAACGAATACTAGAT & \\
\hline \multicolumn{3}{|c|}{ For the identification of leucocinC expression strain (N8-r-lecCl) } \\
\hline Ery-F & CGATACCGTTTACGAAATTGG & 52 \\
\hline Ery-R & CTTGCTCATAAGTAACGGTAC & \\
\hline Out-F & ACGAACAAAACAGTTGCG & 52.5 \\
\hline Out-R & TTCTCTGCCATACTGGCTC & \\
\hline
\end{tabular}

0.2. Afterward, $200 \mu \mathrm{l}$ of the cultures were inoculated into $20 \mathrm{~mL}$ of SGM17 medium in a $50 \mathrm{~mL}$ triangular flask. Growth profiles were monitored by measuring $\mathrm{OD}_{600}$ for $12 \mathrm{~h}$ at $30^{\circ} \mathrm{C}$. All tests were performed in triplicate.

\section{Anti-bacterial Activity}

Agar diffusion assay was performed in triplicate to detect leucocin $\mathrm{C}$ and nisin activities of the culture supernatants of N8, N8p-lecCI, N8-r-lecCI, and NZ9000-p-lecCI. In brief, $20 \mathrm{~mL}$ of soft agar and $80 \mu \mathrm{l}$ of the corresponding indicator strain $\left(5 \times 10^{8} \mathrm{CFU} / \mathrm{mL}\right)$ were mixed and poured onto a plate with Oxford cups. The holes of the dried agar plates were added with $150 \mu \mathrm{l}$ of the pasteurized supernatant $\left(75^{\circ} \mathrm{C}, 10 \mathrm{~min}\right)$ from the overnight cultures of $L$. lactis strains. The plates were incubated overnight at corresponding temperature.

\section{SDS-PAGE and Identification of the Leucocin C Activity Band}

Total protein was obtained from $100 \mathrm{~mL}$ of the cell-free overnight culture supernatants of NZ9000 (blank control) and NZ9000-plecCI (leucocin C) and precipitated by $50 \%$ ammonium sulfate at $4^{\circ} \mathrm{C}$. The precipitate was centrifuged at $14,000 \times g$ and $4^{\circ} \mathrm{C}$ for $30 \mathrm{~min}$ and released in $1 \mathrm{~mL}$ of sterile water. The concentrated supernatant samples were analyzed by tricine-SDSPAGE (Schägger and von Jagow, 1987). Gels were prepared using $16 \%$ acrylamide resolving gel and $1 \mathrm{~cm}$ of $4 \%$ acrylamide spacer gel. After electrophoresis (Bio-Rad), the gel was divided vertically into two parts; the first part was stained with Coomassie brilliant blue G-250 (Takara, Dalian, China), and the second part was used for testing antimicrobial activity according to the method described earlier (Bhunia et al., 1987). The gel was washed for $30 \mathrm{~min}$ by sterile water and placed in a plate. The plate was poured with soft agar containing L. monocytogenes ATCC19115 and incubated at $37^{\circ} \mathrm{C}$ overnight. 


\section{Comparison of Genetic Stability}

The expression strains N8-p-lecCI (plasmid expression method) and N8-r-lecCI (homologous recombination expression method) were inoculated into $1.5 \mathrm{~mL}$ tube containing SMG17 broth (non-selective conditions). The strains were cultivated at $30^{\circ} \mathrm{C}$ for $8 \mathrm{~h}$, transferred into a second tube, and cultivated under the same conditions. Serial transferring was carried out 70 times, and each transfer was referred to as 10 generation times (results not shown). A single colony was harvested to inspect the stability of the strain by calculating the percentage of leucocin $\mathrm{C}$ expressing cells in the population.

\section{Determination of the Minimum Inhibitory Concentration}

The minimum inhibitory concentrations (MICs) of EDTA and N8-r-lecCI supernatant against $L$. monocytogenes WSLC1018, L. monocytogenes ATCC 19115, Staphylococcus aureus ATCC6538, Staphylococcus aureus ATCC29213, E. coli ATCC25922, E. coli O157:H7, Salmonella Enteritidis ATCC 14128 and M. luteus A1CNCIMB 861666 were determined using a broth micro-dilution assay (Clinical and Laboratory Standards Institute [CLSI], 2014). These strains were adjusted to a final concentration of $10^{5} \mathrm{CFU} / \mathrm{mL}$ in the corresponding broth, and $100 \mu \mathrm{l}$ of the prepared suspension was added to the twofold serial dilutions of antibacterial agents $(100 \mu \mathrm{l})$. After $24 \mathrm{~h}$ of incubation at $37^{\circ} \mathrm{C}$, MIC was defined as the lowest antimicrobial concentration that did not result in visible growth. All tests were performed in triplicate.

\section{Checkerboard Assay}

Checkerboard method (Martinez-Irujo et al., 1996) is usually used to evaluate the interaction of different drugs. In this study, each combination $(\mathrm{A} \times \mathrm{B})$ of compound $\mathrm{A}(50 \mu \mathrm{l}$ of EDTA) and B (50 $\mu$ l of N8-r-lecCI supernatant) was diluted by twofold along the ordinate and abscissa axes in a 96-well microtiter plate. The final concentrations of the compounds ranged from 1/32-2 times the MIC for EDTA and 1/64-2 times the MIC for the N8-r-lecCI supernatant. The pathogenic bacteria were adjusted to the final concentration of $10^{5} \mathrm{CFU} / \mathrm{mL}$ in the corresponding broth $(100 \mu \mathrm{l})$ and added to the combinations of the compounds. The plate was incubated at $37^{\circ} \mathrm{C}$ for $24 \mathrm{~h}$. All tests were performed in triplicate.

\section{Time-Kill Assay in Pasteurized Milk}

Listeria monocytogenes, as a common food contaminating bacterium poses significant threat to public health (Jemmi and Stephan, 2006). According to preliminary checkerboard assays, the positive interaction between EDTA and the N8-rlecCI supernatant against L. monocytogenes ATCC 19115 was chosen for time-kill assay in pasteurized milk. The growth curve-based time-kill assay was determined according to a previous method with minor modification (Garcia et al., 2010; Shi et al., 2017). The experimental tubes containing pasteurized milk initially inoculated with $10^{5} \mathrm{CFU} / \mathrm{mL}$ pathogens were added with either single antibacterial agent or the combination of antibacterial agents. The tube with pathogen was used as control. The samples were cultured at $4^{\circ} \mathrm{C}$ (refrigeration temperature) and $25^{\circ} \mathrm{C}$ (room temperature) for $24 \mathrm{~h}$. Bacterial counts were determined by spreading appropriate dilutions on TSB-YE agar every $4 \mathrm{~h}$. The plates were incubated at $37^{\circ} \mathrm{C}$ overnight, and bacterial colonies were counted. In these experiments, the concentration of EDTA was consistent with $1 / 2$ of the MIC, and the concentration of the N8-r-lecCI supernatant was consistent with the MIC. All tests and measurements were performed in triplicate.

\section{Scanning Electron Microscopy (SEM)}

Logarithmic-phase bacteria (L. monocytogenes ATCC 19115) were collected at $4000 \mathrm{~g}$ for $5 \mathrm{~min}$ and washed twice with PBS $\left(\mathrm{pH}\right.$ 7.4). The cells were suspended in PBS $\left(\mathrm{OD}_{600}=0.2\right)$ and treated with EDTA $(0.125 \mathrm{mg} / \mathrm{mL}) / \mathrm{N} 8-\mathrm{r}$-lecCI supernatant (MIC) or their combination [EDTA $(0.125 \mathrm{mg} / \mathrm{mL})$ and N8-r-lecCI supernatant (MIC)] for $1 \mathrm{~h}$. The bacterial cells without antimicrobial treatment were similarly processed and used as controls. After incubation, the cells were washed with PBS and fixed overnight at $4{ }^{\circ} \mathrm{C}$ with $2.5 \%$ glutaraldehyde. The cells were washed in the same buffer and dehydrated using gradient ethanol concentrations ranging from 50 to $100 \%$, with each gradient for about $15 \mathrm{~min}$. Ethanol was replaced with tertiary butyl alcohol. The samples were

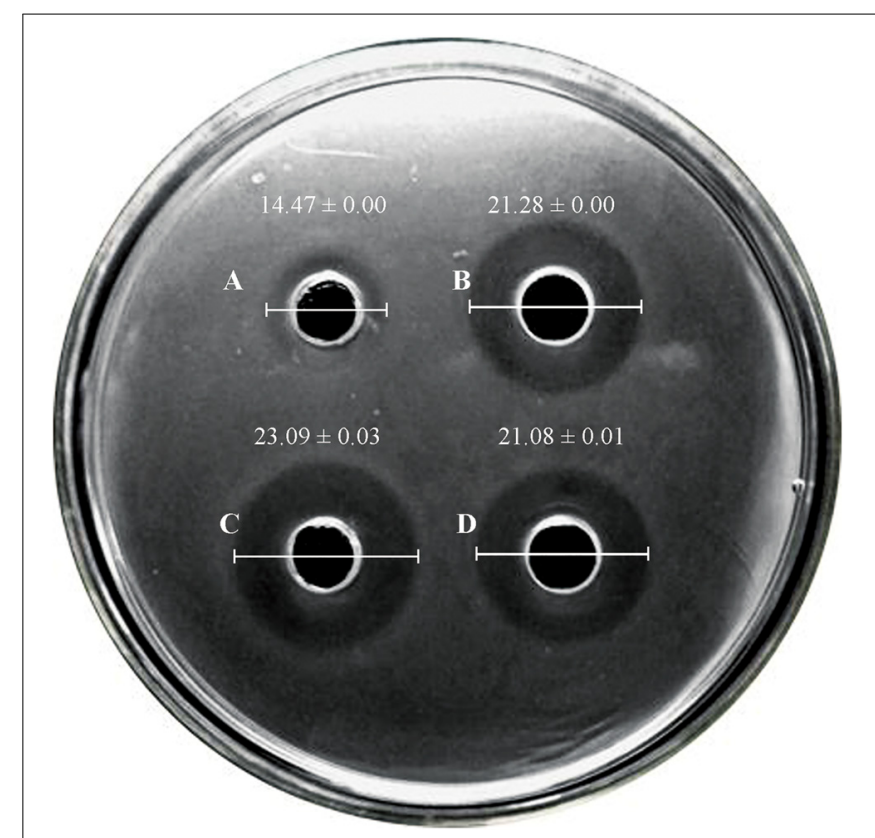

FIGURE 1 | Results of agar-diffusion experiment with leucocin C-producing $L$. lactis and the wild type N8 (indicator strain: L. monocytogenes WSLC 1018). Three independent experiments were conducted, and the image represents the results of one of the experiments (unit: $m m$ ). (A) L. lactis N8; (B) L. lactis N8-p-lecCl; (C) L. lactis N8-r-lecCl; and (D) L. lactis NZ9000-p-lecCl. The difference between two groups was compared by $t$-test, the diameter of inhibitions zone of N8-p-lecCl, N8-r-lecCl and NZ9000-p-lecCl were significantly different $(P<0.05)$ compared with N8. 

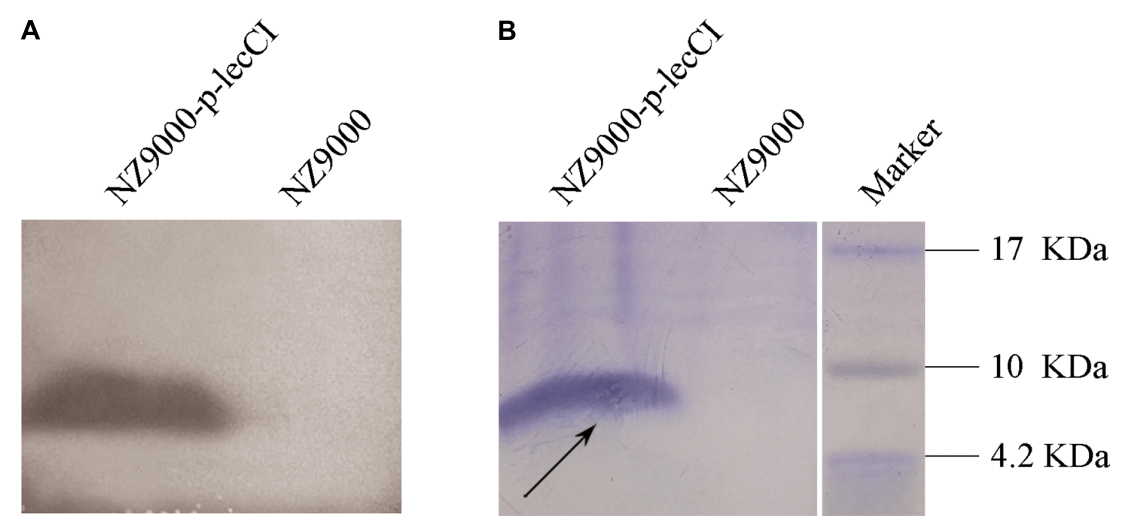

FIGURE 2 | SDS-PAGE of supernatant concentrations from overnight cultures of L. lactis NZ9000 (control) and leucocin C-producing strain L. lactis NZ9000-p-lecCl. (A) The gel was covered with soft agar containing L. monocytogenes WSLC1018. (B) Coomassie blue G-250-stained gel. A putative leucocin C band (black arrow) in (B) and the corresponding inhibition zone in (A) appeared between 4.2 and $10 \mathrm{kDa}$. The actual size of leucocin $\mathbf{C}$ is about $4.6 \mathrm{kDa}$.

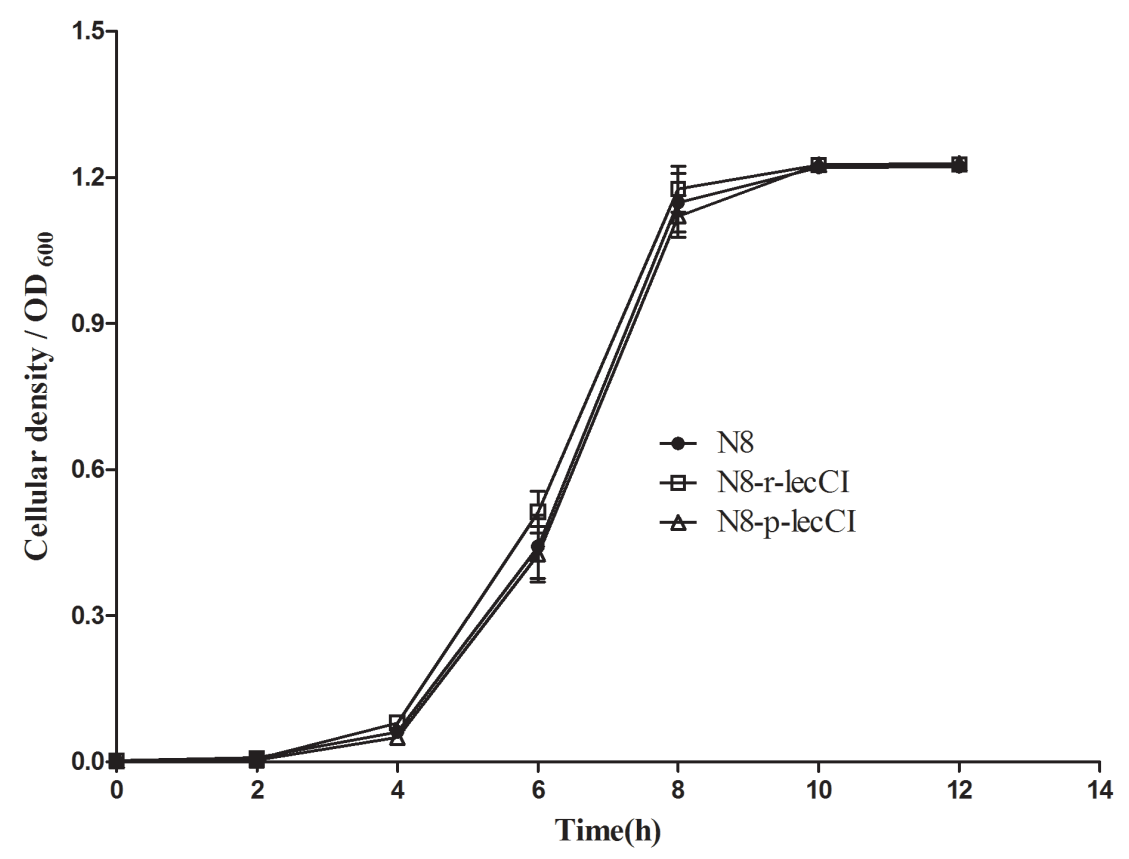

FIGURE 3 | Growth profiles of N8, N8-p-lecCl and N8-r-lecCl in SMG17 (non-selective pressure). The cellular density of the cultures was monitored once every $2 \mathrm{~h}$ by measuring OD600 for $12 \mathrm{~h}$. All growth curve experiments were carried out in triplicate, and each point represents the average of separate experiments with standard deviation indicated by vertical bars. The difference between two groups was compared by t-test, the growth profiles of different strains exhibited no significant difference.

drop on the plate and prepared for SEM (QUANTA 200) observation.

\section{RESULTS}

\section{Identification of Activity and Protein Band of Leucocin C}

Bacteriocin production was determined by agar diffusion assay on a plate. Leucocin C was effectively secreted by recombinant $L$. lactis strains and shown as inhibition zones on
L. monocytogenes indicator plates (Figure 1). All constructed strains showed excellent anti-listeriosis activity compared with the wild strain N8 (slight inhibition). The inhibitory effect of N8-r-lecCI was more distinct than the plasmid expression strains N8-p-lecCI and NZ9000-p-lecCI, indicating the superior antibacterial activity of N8-r-lecCI. The proteins from the culture supernatants were concentrated and analyzed with SDS-PAGE to confirm whether or not leucocin $\mathrm{C}$ inhibits the growth of L. monocytogenes. Results of Coomassie brilliant Blue G-250 staining indicated the migration of the putative leucocin $\mathrm{C}$ band between 4.2 and $10 \mathrm{kDa}$ (Figure 2B). An inhibition zone was 
TABLE 3 | Antimicrobial spectrum of N8 and N8-r-lecCl.

\begin{tabular}{lcc}
\hline Indicative bacteria & \multicolumn{2}{c}{ Inhibitory effect } \\
\cline { 2 - 3 } & N8 & N8-r-lecCl \\
\hline S. aureus ATCC 6538 & +++ & ++++ \\
S. aureus ATCC 29213 & +++ & ++++ \\
L. monocytogenes WSLC 1018 & - & +++ \\
L. monocytogenes ATCC 19115 & + & +++ \\
E. coli ATCC 8739 & - & + \\
E. coli O157:H7 & - & + \\
S. Enteritidis ATCC 14128 & - & + \\
M. luteus A1CNCIMB 861666 & +++ & ++
\end{tabular}

(-), absence of inhibitory effect with twofold dilution of supernatant; (+), presence of inhibitory effect with twofold dilution of supernatant; (++), presence of inhibitory effect with fourfold dilution of supernatant; $(+++)$, presence of inhibitory effect with eightfold dilution of supernatant; $(++++)$, presence of inhibitory effect with 32-fold (greater or equal to) dilution of supernatant.

found around the potential leucocin $\mathrm{C}$ band in the second part of the gel which was used for testing antimicrobial activity against L. monocytogenes, whereas no antimicrobial activity was detected in the remaining parts of the gel (Figure 2A). This finding suggested that the protein band in SDS-PAGE is leucocin C. All these results indicated that the constructed strains can successfully secrete leucocin C.

\section{Growth Profiles of Wild and Constructed Strains}

The growth curves of N8, N8-p-lecCI, and N8-r-lecCI in SMG17 (no-selective pressure) are shown in Figure 3. The growth profiles were similar among the wild-type strain N8, N8-p-lecCI, and $\mathrm{N} 8$-r-lecCI. Hence, the growth of N8 was not affected by the expression of leucocin C.

\section{Determination of Genetic Stability}

The genetic stability of different lecCI expression methods was compared. The genetic stability of N8-r-lecCI and N8-p-lecCI was tested by continuously reculturing in SGM17 broth without selective pressure for 500 and 700 generation times. At the 500th generation time, the percentage of leucocin $\mathrm{C}$ expression cells of population of N8-p-lecCI reduced to $99.33 \pm 0.47 \%$ and this figure dropped to $98.33 \pm 0.47 \%$ after 700 generations. By contrast, N8-r-lecCI maintained excellent genetic stability (the percentage of leucocin C expression cells is $100 \%$ ) after 700 generation times. Hence, homologous recombination (lecC-R expression method) was superior to lec $C$-P expression method because the plasmid of N8-p-lecCI can be lost in the absence of antibiotic pressure.

\section{Determination of Antimicrobial Spectrum and Antimicrobial Activity}

To verify the advantages of the co-expression strain N8-r-lecCI in terms of scope and activity of bacteriostasis, we compared it with the wild-type strain N8. The results of antimicrobial spectrum analysis are shown in Table 3 . The pasteurized supernatant $\left(75^{\circ} \mathrm{C}\right.$ for $10 \mathrm{~min}$ ) from N8-r-lecCI inhibited the growth of the eight

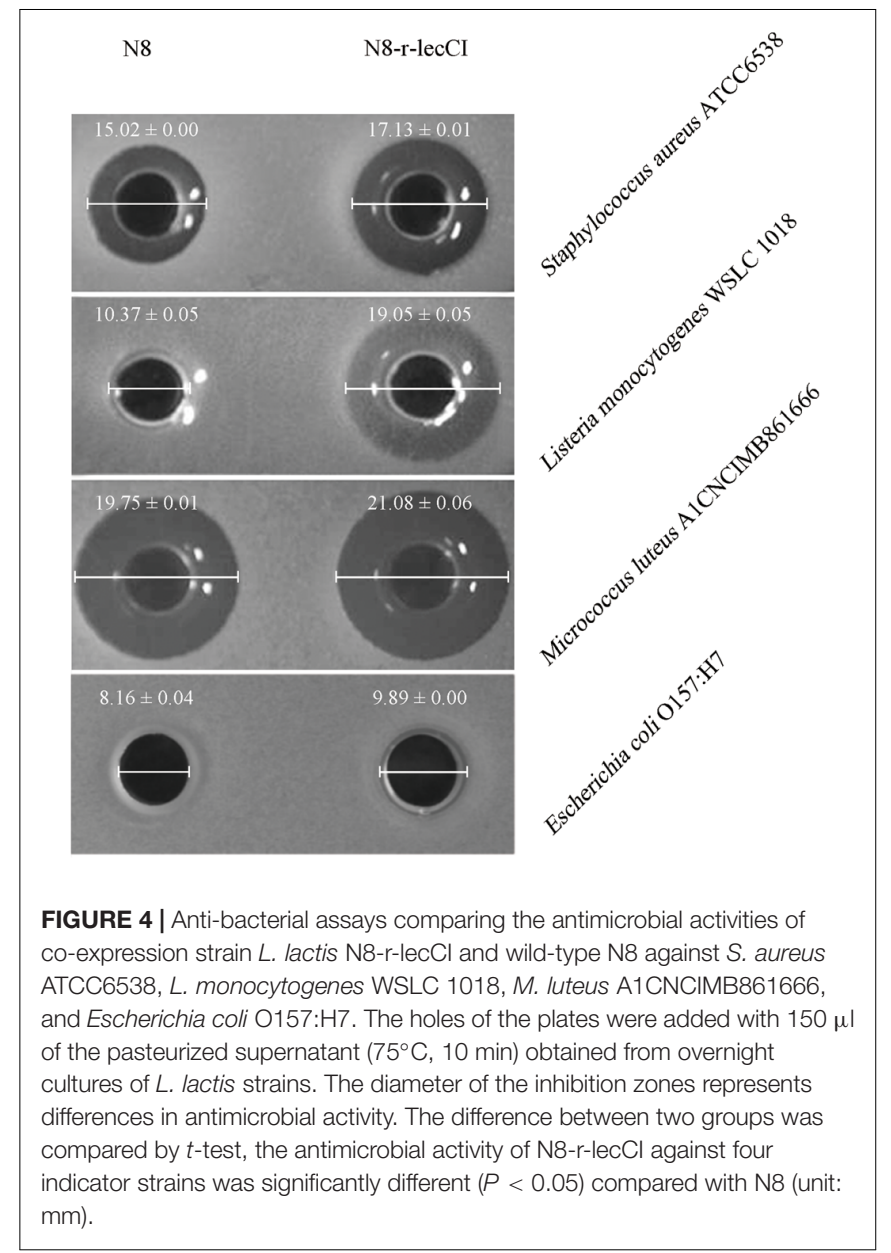

strains tested, and the wild-type strain N8 inhibited only four strains. The antimicrobial spectrum of the recombinant strain N8-r-lecCI evidently increased. As shown in Figure 4, the coexpression strain N8-r-lecCI was superior to the parental strain N8 in terms of bacteriostatic activity against S. aureus ATCC6538, L. monocytogenes WSLC 1018, M. luteus A1CNCIMB861666, and E. coli O157:H7.

\section{Effects of N8-r-lecCl Supernatant Alone or in Combination With EDTA}

The activities of the N8-r-lecCI supernatant and EDTA against three common foodborne pathogens alone or in combination are summarized in Table 4 . The N8-r-lecCI supernatant and EDTA showed different antimicrobial activities against the tested strains based on the calculated MICs. The MIC of the N8-r-lecCI supernatant decreased by $75 \%$ in the presence of $0.0625 \mathrm{mg} / \mathrm{mL}$ EDTA against L. monocytogenes ATCC 19155 and decreased by $75 \%$ in the presence of $0.0312 \mathrm{mg} / \mathrm{mL}$ EDTA against S. aureus ATCC 6538. The combination of EDTA and N8-r-lecCI supernatant exhibited bactericidal effect on E. coli O157:H7, and the MIC of the N8-r-lecCI supernatant decreased by $87.5 \%$ in the presence of $0.625 \mathrm{mg} / \mathrm{mL}$ EDTA. EDTA and the N8-r-lecCI supernatant showed weak or even no antibacterial activities when used alone at this low concentration. 
TABLE 4 | Minimum inhibitory concentrations (MICs) of L. lactis N8-r-lecCl supernatants alone and in combination with EDTA against common foodborne strains.

\begin{tabular}{|c|c|c|c|c|}
\hline \multirow[t]{3}{*}{ Strains } & \multicolumn{4}{|c|}{ MIC (range) of compounds } \\
\hline & \multicolumn{2}{|c|}{ Alone } & \multicolumn{2}{|c|}{ Combination } \\
\hline & EDTA (mg/mL) & Supernatant & EDTA (mg/mL) & Supernatant \\
\hline L. monocytogenes ATCC 19115 & 0.25 & $1 / 8 \times$ & 0.0625 & $1 / 32 \times$ \\
\hline S. aureus ATCC 6538 & 0.0625 & $1 / 64 \times$ & 0.03125 & $1 / 256 \times$ \\
\hline E. coli O157:H7 & 2.5 & $1 / 2 \times$ & 0.625 & $1 / 16 x$ \\
\hline
\end{tabular}

(×), multiple.
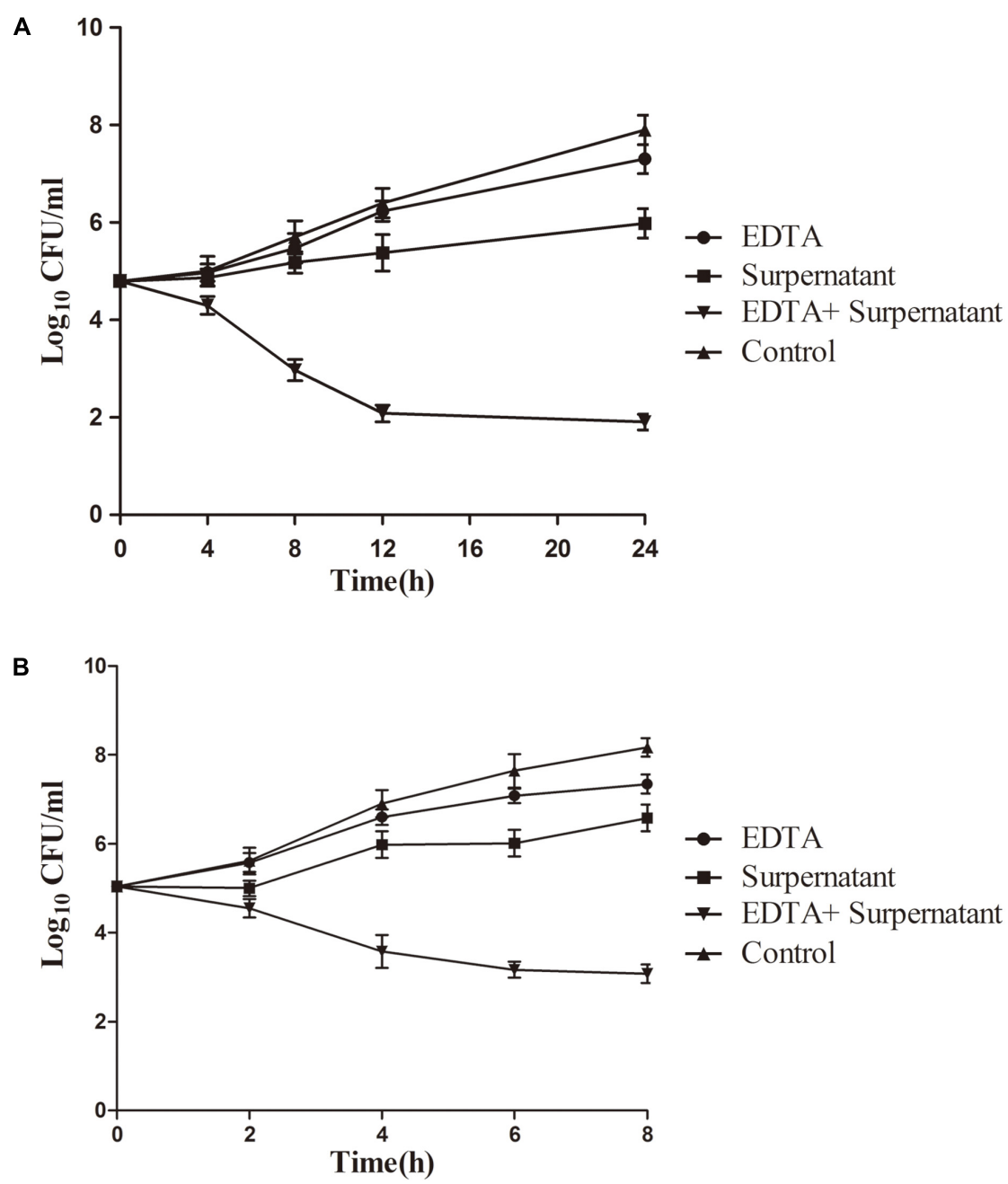

FIGURE 5 | Time-kill curves for EDTA and N8-lecCl supernatant alone or in combination against L. monocytogenes ATCC 19155 in pasteurized milk at (A) refrigeration temperature $\left(4^{\circ} \mathrm{C}\right)$ and $(\mathbf{B})$ room temperature $\left(25^{\circ} \mathrm{C}\right)$. The strains were treated with EDTA $(0.125 \mathrm{mg} / \mathrm{mL})$, N8-r-lecCl supernatant $(\mathrm{concentration}$ of the MIC), and EDTA $(0.125 \mathrm{mg} / \mathrm{mL})+\mathrm{N} 8$-r-lecCl supernatant (concentration of the $\mathrm{MIC}$ ) at a starting inoculum concentration of $10^{5} \mathrm{CFU} / \mathrm{mL}$. All time-kill curves were constructed in triplicate, and each point represents the average of separate experiments with standard deviation indicated by vertical bars. The difference between two groups was compared by $t$-test, the antimicrobial effect of EDTA + N8-r-lecCl supernatant was significantly different $(P<0.05)$ compared with EDTA, N8-r-lecCl supernatant and control.

\section{Time-Kill Assay in Pasteurized Milk}

The increased antibacterial activity of the combination of EDTA and the N8-r-lecCI supernatant was further investigated in pasteurized milk to evaluate the practical application of this method. Considering the growth of L. monocytogenes at low temperature, we performed the assays at 4 and $25^{\circ} \mathrm{C}$. As shown in Figure 5, bacterial growth was more effectively inhibited in the sample treated with the mixture 

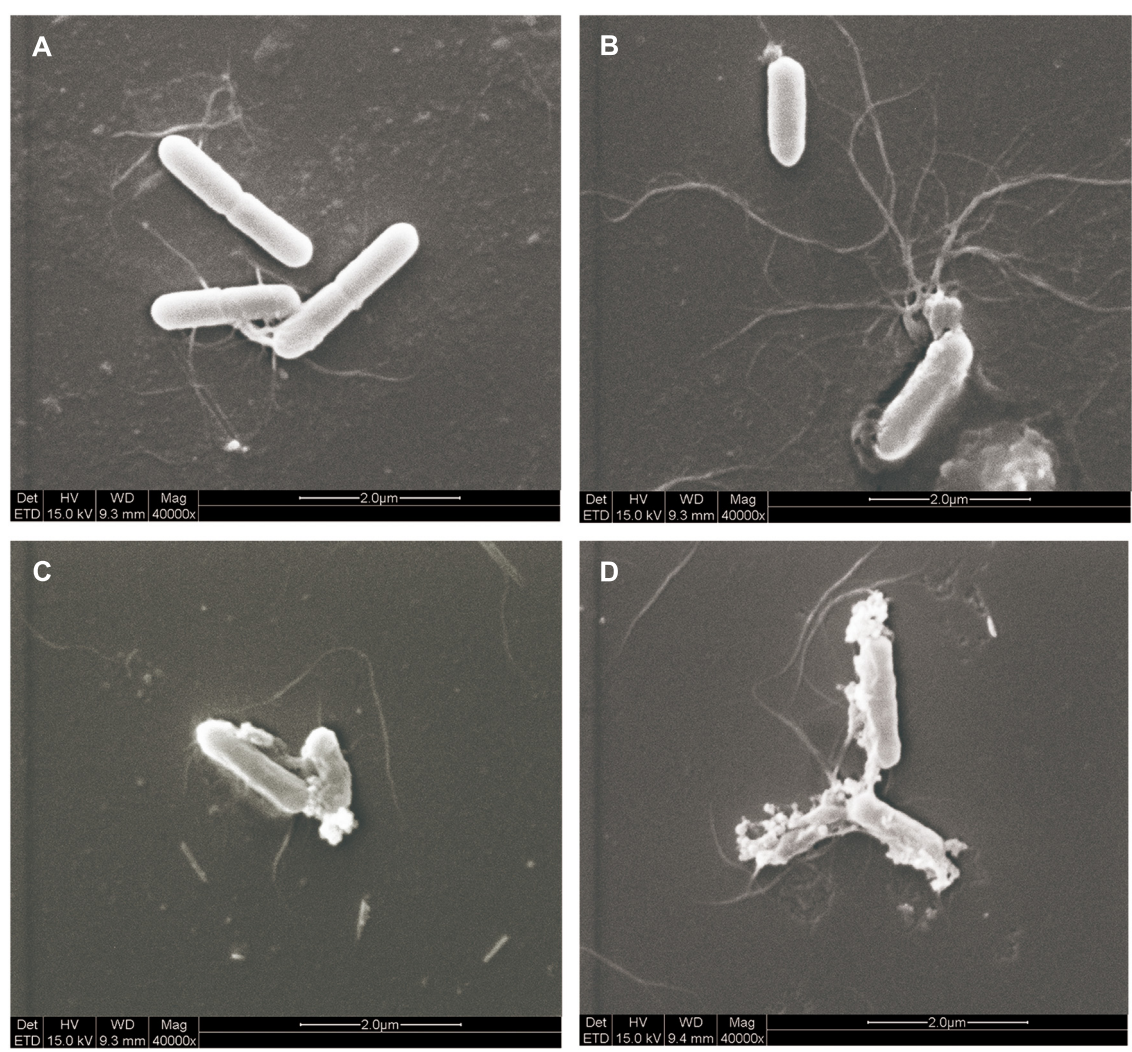

FIGURE 6 | Scanning electron microscopy (SEM) observation of L. monocytogenes ATCC 19155 treated with EDTA and N8-r-lecCl supernatant alone and in combination. (A) Control cells (no treatment), (B) cells treated with EDTA $(0.125 \mathrm{mg} / \mathrm{mL})$, (C) cells treated with the N8-r-lecCl supernatant (concentration of the MIC), and (D) cells treated with EDTA and the N8-r-lecCl supernatant.

of EDTA and N8-r-lecCI supernatant at both temperatures compared with that in the sample treated with a single antibacterial substance. The combination of EDTA and the N8-r-lecCI supernatant reduced the viable bacterial count by more than $2 \log _{10} \mathrm{CFU} / \mathrm{mL}$ at both temperatures, indicating a positive interaction (Knezevic et al., 2013). The effect of the combination in pasteurized milk corresponded to the results presented in checkerboard assay. The results revealed that the combination of EDTA and N8-r-lecCI supernatant exerts a strong bactericidal effect in pasteurized milk against L. monocytogenes.

\section{Effect of Antimicrobials on Bacterial Morphology}

Morphological changes in L. monocytogenes cells were observed through SEM analysis to intuitively elucidate the antibacterial effect of EDTA and the N8-r-lecCI supernatant alone or in combination. As shown in Figure 6, cell damage was observed considering the evident changes in the cell morphology. The control cells maintained a relatively intact cell morphology with a smooth surface (Figure 6A), and the cells treated with EDTA at the $1 / 2$ MIC concentration showed slight damage (Figure 6B). Moreover, the cells treated with the N8-r-lecCI supernatant at the MIC concentration showed relatively more severe damage than those treated with EDTA alone (Figure 6C). The significant cell damage was observed in the sample treated with EDTA + N8r-lecCI supernatant. Most of the outermost layer of the bacterial cells disappeared, and the cell inclusions leaked, leading to the death of bacteria. These results revealed that the inhibition of bacterial growth could be due to the membrane disruption of cells, that is, a stronger antibacterial activity causes more severe cell damage. This assay confirmed that the combination of EDTA and N8-r-lecCI exhibited strong antibacterial activity.

\section{DISCUSSION}

The food-grade strain L. lactis N8 was used as the original strain because of its potential as nisin-leucocin $\mathrm{C}$ co-expression carrier. The results of agar diffusion assay and SDS-PAGE verified that the constructed strains can successfully secrete leucocin $\mathrm{C}$ and nisin, and the secreted leucocin $C$ exhibited distinct inhibitory effect against Listeria monocytogenes. It is also worth noting that the expression of leucocin C did not influence the growth of strains.

Accumulating evidences indicated that serial passage of plasmid-borne strains expressing a protein often result in genetic instability (O'Kennedy et al., 2000), which is an important factor that should be considered when developing recombinant strains for commercial application in industrial fermentation. 
Therefore, the genetic stability of different lecCI expression methods was compared. Homologous recombination method (N8-r-lecCI) was superior to plasmid expression method (N8p-lecCI) because the plasmid of N8-p-lecCI can be lost in the absence of antibiotic pressure. In addition, the relative advantage of N8-r-lecCI compared with N8-p-lecCI is that nonfood source gene was introduced into the expression host. This result verified that the recombinant strain N8-r-lecCI has excellent genetic stability and can stably coexpress nisin-leucocin $\mathrm{C}$, which means it is more suitable for food fermentation and application.

The co-production strain N8-r-lecCI exhibits broad activity spectrum and highly efficient bacteriostatic ability against Grampositive foodborne pathogens. Several studies have demonstrated that nisin show additive or synergistic effects when used in combination with other antimicrobial agents (Branen and Davidson, 2004; Field et al., 2016; Shi et al., 2017). However, to the best of our knowledge, no information regarding the antibacterial activity of nisin co-expression with leucocin $\mathrm{C}$ or in combination with leucocin $\mathrm{C}$ was available in literature. Our study first demonstrated that the co-expression of these two bacteriocins which have different modes of action results in highly efficient antimicrobial activity against Listeria monocytogenes and Staphylococcus aureus. It is a novel combination that is worthy of further investigation.

The food grade chelators EDTA and the N8-r-lecCI supernatant were combined to further enhance the antimicrobial activity of the N8-r-lecCI supernatant. Previous studies have demonstrated that EDTA could be used in the food industry due to its active antibacterial activity and its safety (Heimbach et al., 2000). Our study showed the synergistic antibacterial activity of N8-r-lecCI supernatant and EDTA against L. monocytogenes WSLC1018 and E. coli ATCC25922, and enhanced activity against S. aureus ATCC 6538. Previous reports described that the combination of nisin and EDTA can enhance antimicrobial ability against Gram-negative bacteria and L. monocytogenes (Zhang and Mustapha, 1999; Mastromatteo et al., 2010; Norhana et al., 2012). Several studies have explained the reason regarding the antibacterial efficiency of the combination of nisin and EDTA (Branen and Davidson, 2004). EDTA could release up to $50 \%$ of the lipopolysaccharide (LPS) to affect the outer membrane permeability (Leive, 1965), thereby increasing the susceptibility of cells to nisin. Hence, we hypothesized that EDTA could contribute to efficient binding of leucocin $\mathrm{C}$ to mannose phosphotransferase permease, which serves as target in sensitive cells (Kjos et al., 2009; Wan et al., 2013). This assumption must be further investigated. In the present study, the results revealed the positive interaction among leucocin $\mathrm{C}$,

\section{REFERENCES}

Barbosa, A. A., Mantovani, H. C., and Jain, S. (2017). Bacteriocins from lactic acid bacteria and their potential in the preservation of fruit products. Crit. Rev. Biotechnol. 37, 1-13. doi: 10.1080/07388551.2016.1262323

Barefoot, S. F., and Klaenhammer, T. R. (1983). Detection and activity of lactacin B, a bacteriocin produced by Lactobacillus acidophilus. Appl. Environ. Microbiol. $45,1808-1815$. nisin, and EDTA against some foodborne strains. In addition, the organic acids of the N8-r-lecCI fermentation supernatant helped to suppress the pathogens. Organic acids are widely used for food preservation (Young and Foegeding, 1993). The antimicrobial activity of nisin or other bacteriocins against $L$. monocytogenes F6854 can be enhanced in the presence of organic acids (Smith et al., 2016). Overall, the antibacterial activity of L. lactis N8-rlecCI supernatant can be further enhanced in the presence of the low concentration of EDTA.

The practical antibacterial effect of this combination was verified in a food model through time-kill assay. The effect of the combination in pasteurized milk was consistent with the result presented in checkerboard assay, which shows excellent antimicrobial activity in pasteurized milk preservation. The current standards of pasteurization appear to be adequate for public health assurance of milk safety (Holsinger et al., 1997). However, outbreaks associated with pasteurized milk continue to occur (De Buyser et al., 2001; Centers for Disease Control and Prevention, 2008). The combination of bacteriocins has excellent antimicrobial potential in pasteurized milk preservation.

\section{CONCLUSION}

Lactococcus lactis N8-r-lecCI co-expressing nisin and leucocin $\mathrm{C}$ is characterized by high genetic stability and antibacterial efficiency, and exhibits high potential in food preservation and processing.

\section{AUTHOR CONTRIBUTIONS}

DZ, YF, and MQ designed the experiments. YF, XW, and WQ performed all the major experiments. DM, FL, and MQ analyzed the experimental results. DM and PS provided the additional experimental assistance. YF and DZ wrote the manuscript. OK and MQ helped to revise the manuscript. MQ and HX provided the laboratory equipment and place.

\section{FUNDING}

This work was supported by the National Natural Science Foundation of China (31770102), the Sino-Swiss Science and Technology Cooperation Project supported by the Ministry of Science and Technology of the People's Republic of China (2015DFG32140).

Bhunia, A. K., Johnson, M., and Ray, B. (1987). Direct detection of an antimicrobial peptide of Pediococcus acidilactici in sodium dodecyl sulfate-polyacrylamide gel electrophoresis. J. Ind. Microbiol. Biotechnol. 2, 319-322. doi: 10.1007/ BF01569434

Branen, J. K., and Davidson, P. M. (2004). Enhancement of nisin, lysozyme, and monolaurin antimicrobial activities by ethylenediaminetetraacetic acid and lactoferrin. Int. J. Food Microbiol. 90, 63-74. doi: 10.1016/s0168-1605(03) 00172-7 
Campion, A., Morrissey, R., Field, D., Cotter, P. D., Hill, C., and Ross, R. P. (2017). Use of enhanced nisin derivatives in combination with food-grade oils or citric acid to control Cronobacter sakazakii and Escherichia coli O157:H7. Food Microbiol. 65, 254-263. doi: 10.1016/j.fm.2017.01.020

Capozzi, V., Russo, P., Dueñas, M., López, P., and Spano, G. (2012). Lactic acid bacteria producing B-group vitamins: a great potential for functional cereals products. Appl. Microbiol. Biotechnol. 96, 1383-1394. doi: 10.1007/s00253-0124440-2

Centers for Disease Control and Prevention (2008). Outbreak of Listeria monocytogenes infections associated with pasteurized milk from a local dairyMassachusetts, 2007. MMWR Morb. Mortal. Wkly. Rep. 57, 1097-1100.

Clinical and Laboratory Standards Institute [CLSI] (2014). Performance Standards for Antimicrobial Susceptibility Testing: Twenty-Fourth Informational Supplement, M100-S24. Wayne, PA: Clinical and Laboratory Standards Institute.

Cole, M. B., Jones, M. V., and Holyoak, C. (1990). The effect of pH, salt concentration and temperature on the survival and growth of Listeria monocytogenes. J. Appl. Bacteriol. 69, 63-72. doi: 10.1111/j.1365-2672.1990. tb02912.x

De Buyser, M.-L., Dufour, B., Maire, M., and Lafarge, V. (2001). Implication of milk and milk products in food-borne diseases in France and in different industrialised countries. Int. J. Food Microbiol. 67, 1-17. doi: 10.1016/S01681605(01)00443-3

Delves-Brougthon, J. (1990). Nisin and its uses as a food preservative. Food Technol. 44, 100-117.

Field, D., Seisling, N., Cotter, P. D., Ross, R. P., and Hill, C. (2016). Synergistic nisinpolymyxin combinations for the control of Pseudomonas biofilm formation. Front. Microbiol. 7:1713. doi: 10.3389/fmicb.2016.01713

Gandhi, M., and Chikindas, M. L. (2007). Listeria: a foodborne pathogen that knows how to survive. Int. J. Food Microbiol. 113, 1-15. doi: 10.1016/j. ijfoodmicro.2006.07.008

Garcia, P., Martinez, B., Rodriguez, L., and Rodriguez, A. (2010). Synergy between the phage endolysin LysH5 and nisin to kill Staphylococcus aureus in pasteurized milk. Int. J. Food Microbiol. 141, 151-155. doi: 10.1016/j. ijfoodmicro.2010.04.029

Grande, M. J., Lucas, R., Abriouel, H., Omar, N. B., Maqueda, M., MartinezBueno, M., et al. (2005). Control of Alicyclobacillus acidoterrestris in fruit juices by enterocin AS-48. Int. J. Food Microbiol. 104, 289-297. doi: 10.1016/ j.ijfoodmicro.2005.03.010

Heimbach, J., Rieth, S., Mohamedshah, F., Slesinski, R., Samuel-Fernando, P., Sheehan, T., et al. (2000). Safety assessment of iron EDTA [sodium iron $\left(\mathrm{Fe}^{3+}\right)$ ethylenediaminetetraacetic acid]: summary of toxicological, fortification and exposure data. Food Chem. Toxicol. 38, 99-111. doi: 10.1016/S0278-6915(99) 00125-8

Holsinger, V. H., Rajkowski, K. T., and Stabel, J. R. (1997). Milk pasteurisation and safety: a brief history and update. Rev. Sci. Tech. 16, 441-451. doi: 10.20506/rst. 16.2.1037

Jemmi, T., and Stephan, R. (2006). Listeria monocytogenes: food-borne pathogen and hygiene indicator. Rev. Sci. Tech. 25, 571-580. doi: 10.20506/rst.25.2.1681

Kaferstein, F. K., Motarjemi, Y., and Bettcher, D. W. (1997). Foodborne disease control: a transnational challenge. Emerg. Infect. Dis. 3, 503-510. doi: 10.3201/ eid0304.970414

Kjos, M., Nes, I. F., and Diep, D. B. (2009). Class II one-peptide bacteriocins target a phylogenetically defined subgroup of mannose phosphotransferase systems on sensitive cells. Microbiology 155, 2949-2961. doi: 10.1099/mic.0. 030015-0

Klaenhammer, T. R. (1993). Genetics of bacteriocins produced by lactic acid bacteria. FEMS Microbiol. Rev. 12, 39-85. doi: 10.1111/j.1574-6976.1993. tb00012.x

Knezevic, P., Curcin, S., Aleksic, V., Petrusic, M., and Vlaski, L. (2013). Phage-antibiotic synergism: a possible approach to combatting Pseudomonas aeruginosa. Res. Microbiol. 164, 55-60. doi: 10.1016/j.resmic.2012.08.008

Kuipers, O. P., de Ruyter, P. G., Kleerebezem, M., and de Vos, W. M. (1998). Quorum sensing-controlled gene expression in lactic acid bacteria. J. Biotechnol. 64, 15-21. doi: 10.1016/S0168-1656(98)00100-X

Laksanalamai, P., Joseph, L. A., Silk, B. J., Burall, L. S., Tarr, L. C., Gerner-Smidt, P., et al. (2012). Genomic characterization of Listeria monocytogenes strains involved in a multistate listeriosis outbreak associated with cantaloupe in US. PLoS One 7:e42448. doi: 10.1371/journal.pone. 0042448

Lambert, J. M., Bongers, R. S., and Kleerebezem, M. (2007). Cre-lox-based system for multiple gene deletions and selectable-marker removal in Lactobacillus plantarum. Appl. Environ. Microbiol. 73, 1126-1135. doi: 10.1128/AEM. 01473-06

Langa, S., Arques, J. L., Medina, M., and Landete, J. M. (2017). Coproduction of colicin V and lactic acid bacteria bacteriocins in lactococci and enterococci strains of biotechnological interest. J. Appl. Microbiol. 122, 1159-1167. doi: 10.1111/jam.13439

LeBlanc, J. G., Van Sinderen, D., Hugenholtz, J., Piard, J.-C., Sesma, F., and de Giori, G. S. (2010). Risk assessment of genetically modified lactic acid bacteria using the concept of substantial equivalence. Curr. Microbiol. 61, 590-595. doi: 10.1007/s00284-010-9657-7

Leive, L. (1965). Release of lipopolysaccharide by EDTA treatment of E. coli. Biochem. Biophys. Res. Commun. 21, 290-296. doi: 10.1016/0006-291X(65) 90191-9

Li, R., Takala, T. M., Qiao, M., Xu, H., and Saris, P. E. (2011). Nisin-selectable food-grade secretion vector for Lactococcus lactis. Biotechnol. Lett. 33, 797-803. doi: 10.1007/s10529-010-0503-6

Lucera, A., Costa, C., Conte, A., and Del Nobile, M. A. (2012). Food applications of natural antimicrobial compounds. Front. Microbiol. 3:287. doi: 10.3389/fmicb. 2012.00287

Martinez-Irujo, J. J., Villahermosa, M. L., Alberdi, E., and Santiago, E. (1996). A checkerboard method to evaluate interactions between drugs. Biochem. Pharmacol. 51, 635-644. doi: 10.1016/S0006-2952(95) 02230-9

Mastromatteo, M., Lucera, A., Sinigaglia, M., and Corbo, M. R. (2010). Synergic antimicrobial activity of lysozyme, nisin, and EDTA against Listeria Monocytogenes in ostrich meat patties. J. Food Sci. 75, M422-M429. doi: 10. 1111/j.1750-3841.2010.01732.x

Norhana, M. N. W., Poole, S. E., Deeth, H. C., and Dykes, G. A. (2012). Effects of nisin, EDTA and salts of organic acids on Listeria monocytogenes, Salmonella and native microflora on fresh vacuum packaged shrimps stored at $4^{\circ} \mathrm{C}$. Food Microbiol. 31, 43-50. doi: 10.1016/j.fm.2012.01.007

O'Kennedy, R. D., Baldwin, C., and Keshavarz-Moore, E. (2000). Effects of growth medium selection on plasmid DNA production and initial processing steps. J. Biotechnol. 76, 175-183. doi: 10.1016/S0168-1656(99) 00187-X

O’Sullivan, L., Ross, R. P., and Hill, C. (2002). Potential of bacteriocin-producing lactic acid bacteria for improvements in food safety and quality. Biochimie 84, 593-604. doi: 10.1016/S0300-9084(02)01457-8

Qiao, M., Immonen, T., Koponen, O., and Saris, P. E. (1995). The cellular location and effect on nisin immunity of the NisI protein from Lactococcus lactis N8 expressed in Escherichia coli and L. lactis. FEMS Microbiol. Lett. 131, 75-80. doi: 10.1016/0378-1097(95)00238-Z

Qiao, M., Ye, S., Koponen, O., Ra, R., Usabiaga, M., Immonen, T., et al. (1996). Regulation of the nisin operons in Lactococcus lactis N8. J. Appl. Microbiol. 80, 626-634. doi: 10.1111/j.1365-2672.1996.tb03267.x

Renault, P. (2002). Genetically modified lactic acid bacteria: applications to food or health and risk assessment. Biochimie 84, 1073-1087. doi: 10.1016/s03009084(02)00029-9

Roberts, R., and Zottola, E. (1993). Shelf-life of pasteurized process cheese spreads made from cheddar cheese manufactured with a nisin-producing starter culture1. J. Dairy Sci. 76, 1829-1836. doi: 10.3168/jds.S0022-0302(93) 77515-3

Schägger, H., and von Jagow, G. (1987). Tricine-sodium dodecyl sulfatepolyacrylamide gel electrophoresis for the separation of proteins in the range from 1 to $100 \mathrm{kDa}$. Anal. Biochem. 166, 368-379. doi: 10.1016/0003-2697(87) 90587-2

Shi, C., Zhang, X., Zhao, X., Meng, R., Liu, Z., Chen, X., et al. (2017). Synergistic interactions of nisin in combination with cinnamaldehyde against Staphylococcus aureus in pasteurized milk. Food Control 71, 10-16. doi: 10.1016/ j.foodcont.2016.06.020

Smith, M. K., Draper, L. A., Hazelhoff, P. J., Cotter, P. D., Ross, R. P., and Hill, C. (2016). A bioengineered nisin derivative, M21A, in combination with food grade additives eradicates biofilms of Listeria monocytogenes. Front. Microbiol. 7:1939. doi: 10.3389/fmicb.2016.01939 
Swetwiwathana, A., and Visessanguan, W. (2015). Potential of bacteriocinproducing lactic acid bacteria for safety improvements of traditional Thai fermented meat and human health. Meat Sci. 109, 101-105. doi: 10.1016/j. meatsci.2015.05.030

Sybesma, W., Hugenholtz, J., De Vos, W. M., and Smid, E. J. (2006). Safe use of genetically modified lactic acid bacteria in food. Bridging the gap between consumers, green groups, and industry. Electron. J. Biotechnol. 9, 424-448. doi: 10.2225/vol9-issue4-fulltext-12

Velusamy, V., Arshak, K., Korostynska, O., Oliwa, K., and Adley, C. (2010). An overview of foodborne pathogen detection: in the perspective of biosensors. Biotechnol. Adv. 28, 232-254. doi: 10.1016/j.biotechadv.2009. 12.004

Wan, J., Harmark, K., Davidson, B. E., Hillier, A. J., Gordon, J. B., Wilcock, A., et al. (1997). Inhibition of Listeria monocytogenes by piscicolin 126 in milk and Camembert cheese manufactured with a thermophilic starter. J. Appl. Microbiol. 82, 273-280. doi: 10.1046/j.1365-2672.1997.00349.x

Wan, X., Li, R., Saris, P. E., and Takala, T. M. (2013). Genetic characterisation and heterologous expression of leucocin C, a class IIa bacteriocin from Leuconostoc carnosum 4010. Appl. Microbiol. Biotechnol. 97, 3509-3518. doi: 10.1007/ s00253-012-4406-4

Wan, X., Saris, P. E., and Takala, T. M. (2015). Genetic characterization and expression of leucocin B, a class IId bacteriocin from Leuconostoc carnosum 4010. Res. Microbiol. 166, 494-503. doi: 10.1016/j.resmic.2015.04.003
Young, K., and Foegeding, P. (1993). Acetic, lactic and citric acids and pH inhibition of Listeria monocytogenes Scott A and the effect on intracellular $\mathrm{pH}$. J. Appl. Bacteriol. 74, 515-520.

Yousef, A. E., and Lou, Y. (1999). "Characteristics of Listeria monocytogenes important to food processors," in Listeria, Listeriosis, and Food Safety 2nd Edn, eds E. T. Ryser and E. H. Marth (New York, NY: Marcel Dekker, Inc.), 131-224.

Zhang, S. S., and Mustapha, A. (1999). Reduction of Listeria monocytogenes and Escherichia coli O157:H7 numbers on vacuum-packaged fresh beef treated with nisin or nisin combined with EDTA. J. Food Prot. 62, 1123-1127. doi: 10.4315/ 0362-028X-62.10.1123

Conflict of Interest Statement: The authors declare that the research was conducted in the absence of any commercial or financial relationships that could be construed as a potential conflict of interest.

Copyright (c) $2018 \mathrm{Fu}, \mathrm{Mu}$, Qiao, Zhu, Wang, Liu, Xu, Saris, Kuipers and Qiao. This is an open-access article distributed under the terms of the Creative Commons Attribution License (CC BY). The use, distribution or reproduction in other forums is permitted, provided the original author(s) and the copyright owner are credited and that the original publication in this journal is cited, in accordance with accepted academic practice. No use, distribution or reproduction is permitted which does not comply with these terms. 